$\mathrm{TM}-1212$

0102.000

$\operatorname{March~27,1983}$

TUNNEL CONSTRUCTION FOR A DESERTRON

H. Hinterberger and F. R. Huson

The tunnel in this model of construction is $3 / 2$ feet wide by 5 feet high (see Figure 1). It is assumed that the tunnel contains a rail syster and guidance system for:

1. An enclosed car used for transport of $\geq$ people and some tools. The people could sit in comfortable seats and travel at perhaps 25 miles per hour (this would be similar to the London tube but much smaller). The car would be equipped with oxygen in case of helium in the tunnel. There would be bypasses at the service buildines for passing and storage of cars. A computer system rould control the cars. There may be as many as 50 cars.

2. Magnet mover. This "robot" could pick up a magnet and transport it at about 10 miles per hour. Each of six machine straight sections would have openings for insertion and extraction of magnets. The openines would be covered by moveable shielding. The magnet mover would look something like a long centipede and be controlled by the computer system.

3. Alignment Robot. The alignment robot would intercept E.M. waves (microwaves, lasers, (see alignment paper) to determine its position in the tunnel (the sapitta over $150 \mathrm{~m}$ is only $15 \mathrm{~cm}$ ). A very accurate onboari digital level can give level to less than a milliradian. The robot would have an arm to grab the outside of 
the magnet, it would know the relative position of the magnet and the E.M. wave. It would have another arm to loosen (or tighten) the one bolt that holds the magnet in place. These bolts would hold the steel support on the magnet to the support on the tunnel floor. These supports are located about every 10 feet. It could position the magnet and tighten the bolt. This robot would have to be quite heavy ( $\sim 10$ tons) for stability. There could be 2 dozen of these robots working at all times. Their on-board computer would be connected to a central computer for coordinated alignment.

\section{METHOD OF CONSTRUCTION}

We assume the site is relatively flat (see bel ow) and made up of reasonable earth (easy digging). We also assume the right-ofway of about 300 feet is free (given by the state?).

The first step would be to establish a level (to within a few inches) terrain at least 20 feet wide around the whole accelerator. Fills would be 300 feet wide to the outside for muon shielding. A blacktop roadway would be constructed near the tunnel area. It would more or less follow the terrain. Backhoes would be used to trench 20 feet deep. The trench bottom would be level within a few inches. Following this would be a rigging crew to place a reinforcement wire mesh in the tunnel. Then concrete would be poured into the bottom of the trench. A machine similar to a sophisticated snowmobile, that could be controlled remotely, would vibrate and level the concrete to better than 1 inch. Corrugated galvanized metal tunnel hoops (see Figure 1) would be set in place. 
Then workers could come along inside the tunnel hoop and "nail" it together and to the floor. The trench would then be backfilled with a 1 foot berm on top. A rail system would be installed and a support stand for the magnet. 
Cost estionate fox Tunnel.

Site creation

cut on average $15^{\prime}$ deep with 20 bott for .6 miles and fill 3 ' deep and $300^{\prime}$ wide to the to outride for 4 sines

24 fort wide black tope road

$157 \mathrm{~K} / \mathrm{mi}$

Sinrueying, special cases, etc.

* $300 \mathrm{~K} / \mathrm{mi}$

$\frac{43 \% / \mathrm{mi}}{500 \mathrm{~K} / \mathrm{mi}}$

Tunnel.

Backhoe Trenching of 8'uide $\times 20^{\prime}$ dap.

$(31 \mathrm{~K}$ gds $/$ male ge $(120 / \mathrm{hr}) /(60 \mathrm{ydo} / \mathrm{hr}) \quad 62 \mathrm{~K} / \mathrm{m}$

surveying, helpers etc. Rigging crew for wine grid $5 \mathrm{k} / \mathrm{wk}$

$5 \mathrm{~K} / \mathrm{m}$
concrete bottom $10 / \mathrm{ft} . \quad 5 \mathrm{k} / \mathrm{hk}$
$50 \mathrm{~K} / \mathrm{m}$

$15 \mathrm{~K} / \mathrm{n}$ ot $\mathrm{H}_{2}$ bo $\mathrm{K}$

Corrugated tinsel at $24 / f t$.

Sealing material * $10 / \mathrm{ft}$

2 Rigging crew to to place turns to machines.

Backfill

Special problems.

$20 \mathrm{k} / \mathrm{m}$

$5 k / 2$

$5 k / i n$

m

contingency

$127 \mathrm{~K} / \mathrm{s}$

$50 \mathrm{~K} / \mathrm{s}$

$20 \mathrm{~K} / \mathrm{s}$

$60 \mathrm{~K} / \mathrm{s}$

$40 \mathrm{~K} / \mathrm{s}$

$200 \mathrm{k} /$, 
Service buldengp and Straight sections

80 servicebuildings@ $0^{*} / 00 \mathrm{~K}$

6 straight sections $(500 \mathrm{~m}) \mathrm{e}^{8} 5 \mathrm{~K} / \mathrm{m}$.

$8.0 \mathrm{~m}$
$\frac{15.0 \mathrm{~N}_{1}}{23.0 \mathrm{~m}}$

Complete tunnel and machine straight for $R=20 \mathrm{~km}$.

Site preparation

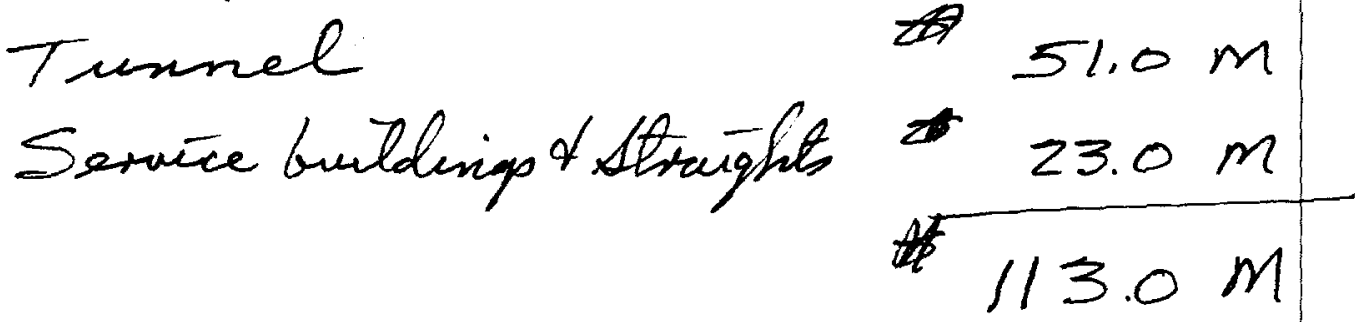




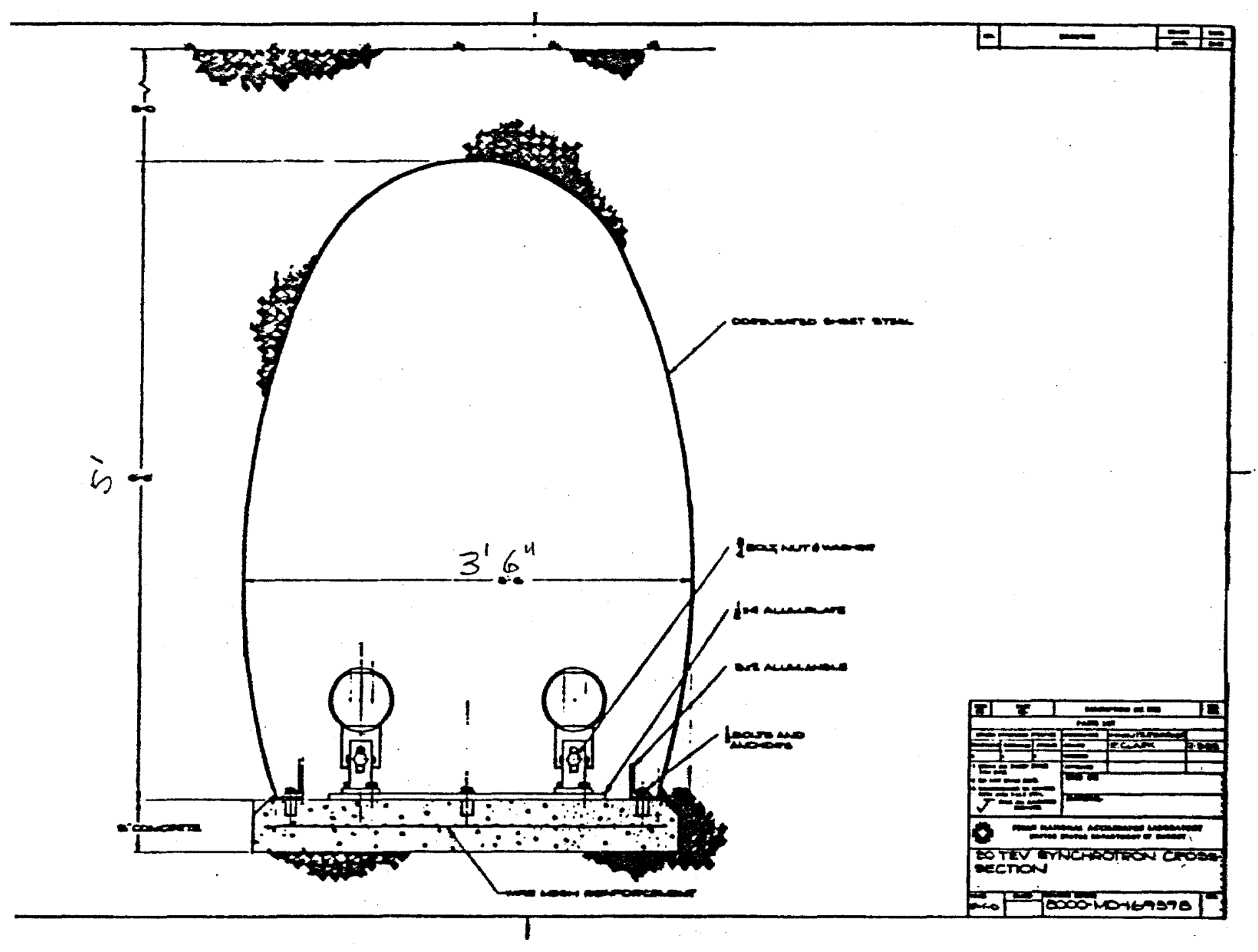




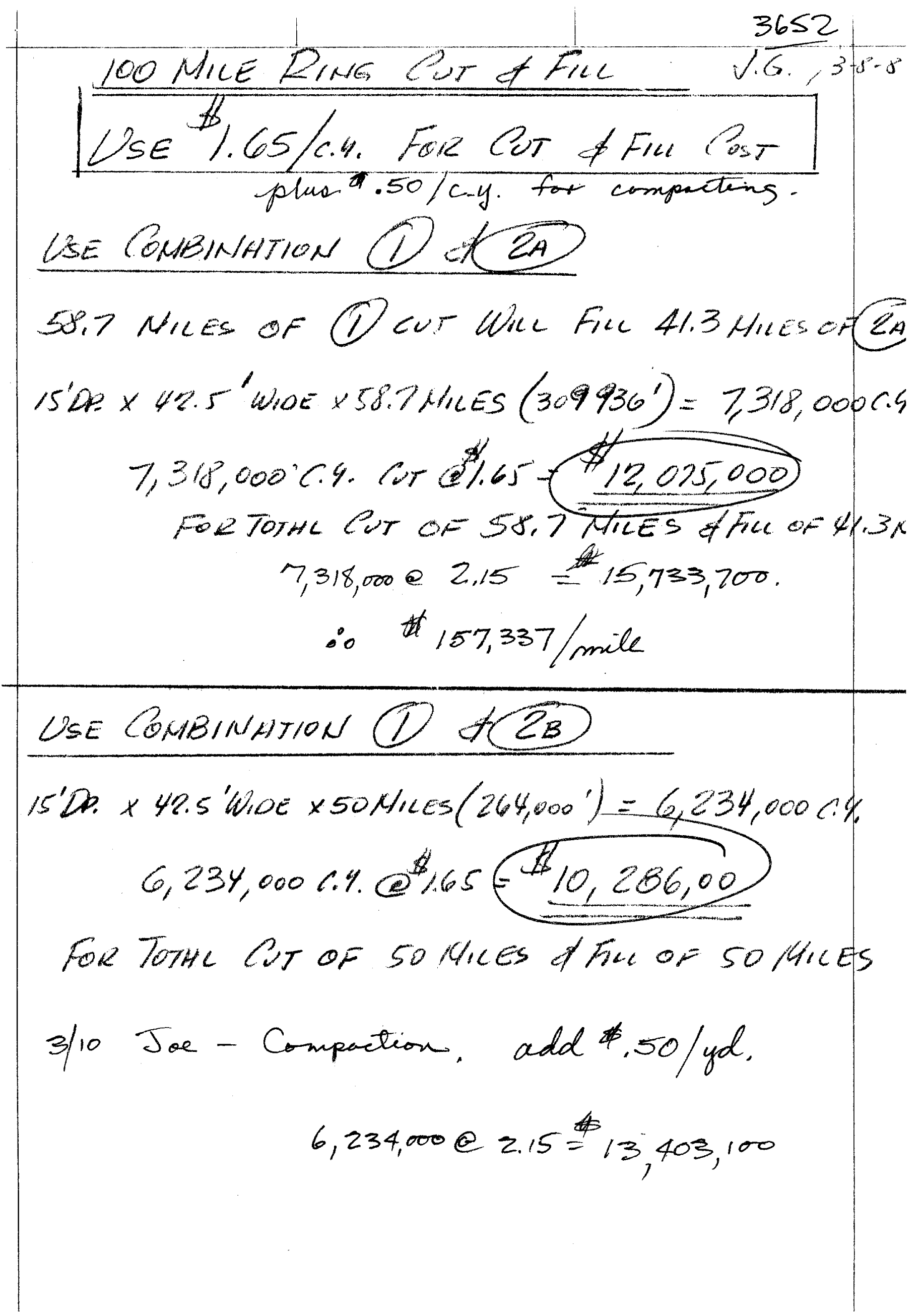




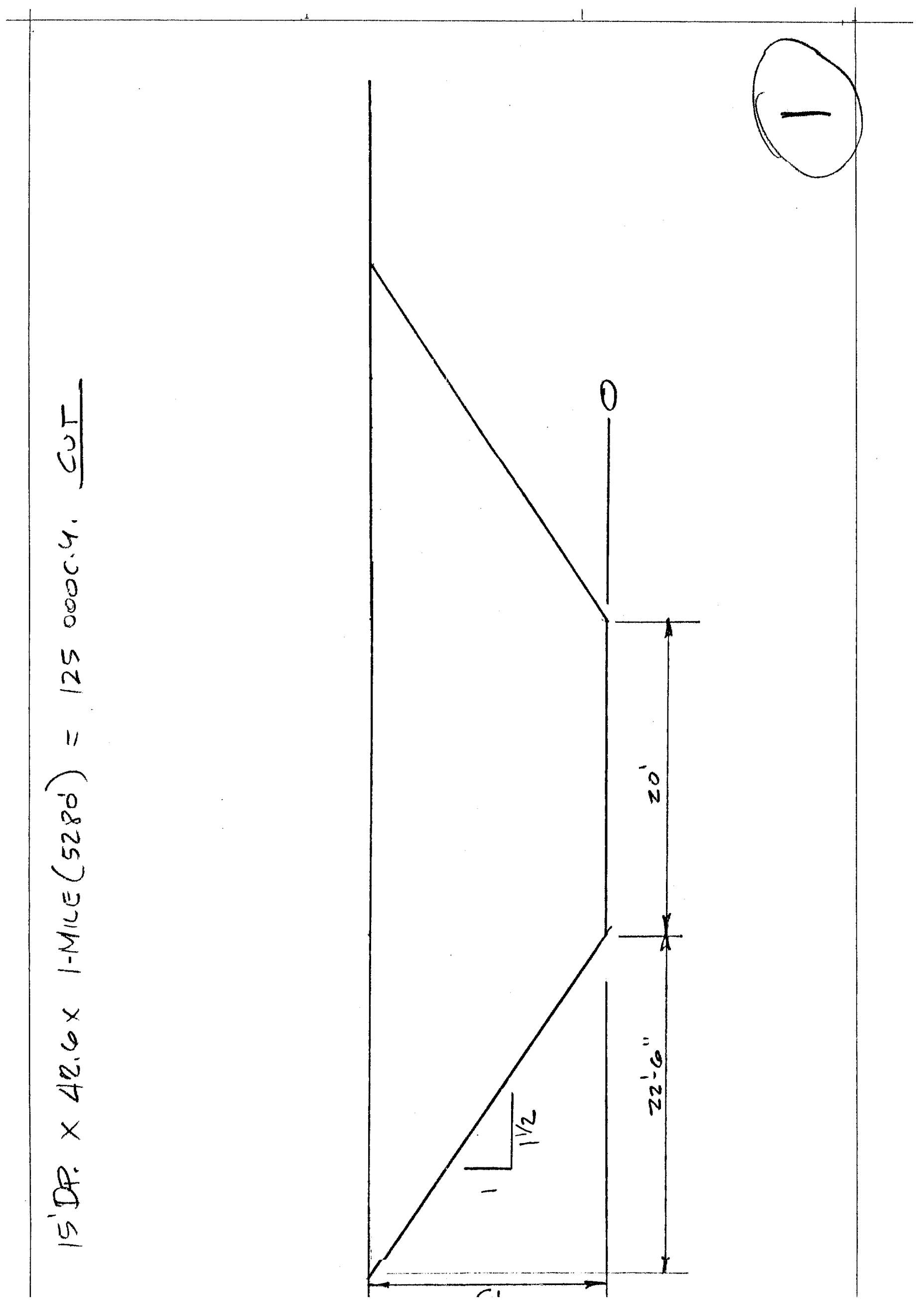




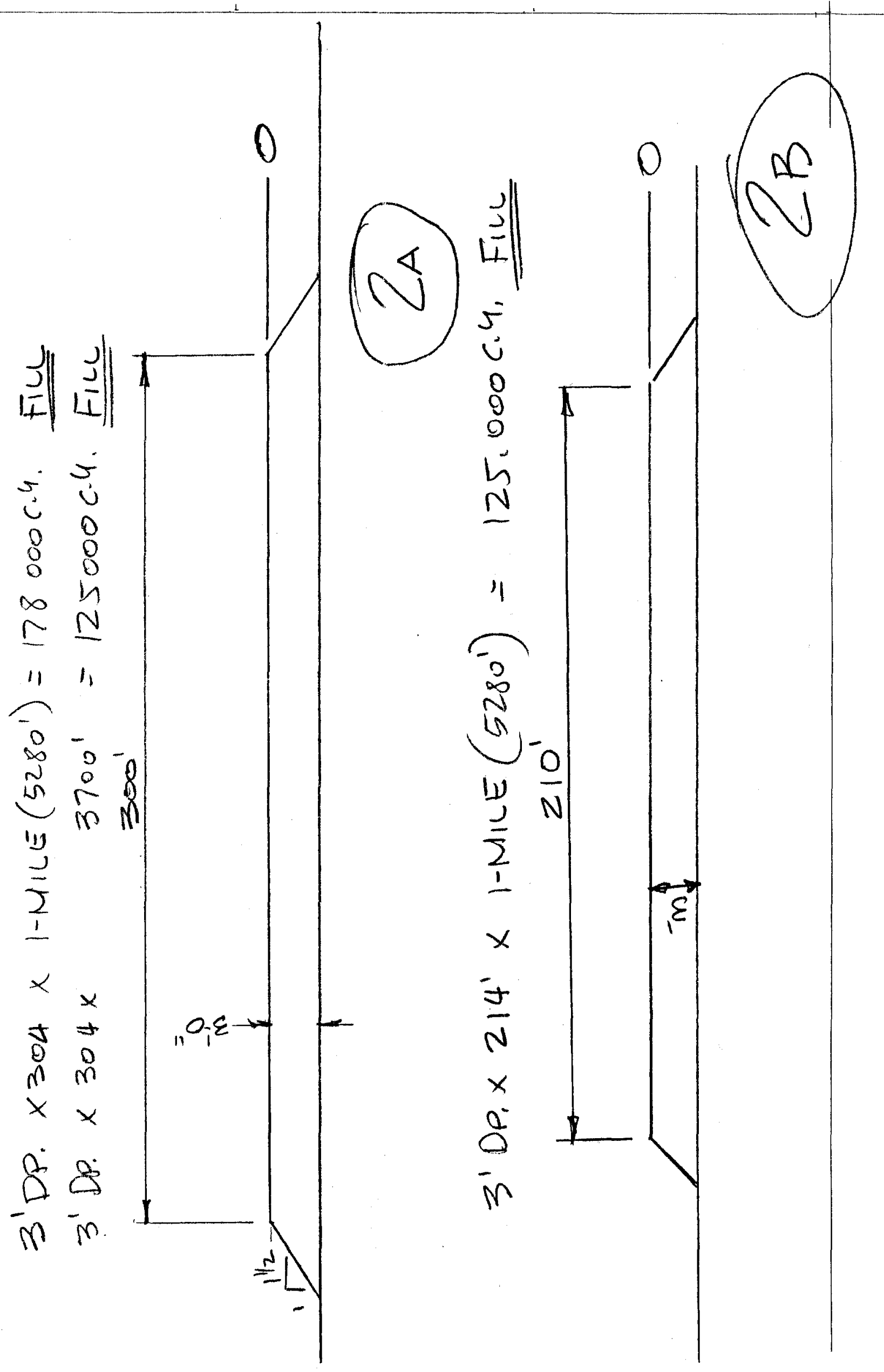

